\title{
The effect of intrinsic foot muscle training on medial longitudinal arch and ankle stability in patients with chronic ankle sprain accompanied by foot pronation
}

\author{
Kyoung A Chung ${ }^{a}$, Eunsang Lee ${ }^{b}$, Seungwon Lee ${ }^{c}$ \\ aDepartment of Occupational Therapy, Dongshin University, NaJu, Republic of Korea \\ ${ }^{b}$ Department of Physcal Therapy, The Graduate School, Sahmyook University, Seoul, Republic of Korea \\ cDepartment of Physcal Therapy, College of Health and Welfare, Sahmyook University, Seoul, Republic of Korea
}

\begin{abstract}
Objective: The purpose of this study was to investigate whether the intrinsic foot muscle training method can improve the medial longitudinal arch in patients with chronic ankle injury and with pronated feet, as well as to investigate for the most effective exercise method for these patients.

Design: Randomized controlled trial.

Methods: Thirty men and women with pronated feet had participated in this study and were allocated to either the short foot exercise group (SFEG) or the towel curl exercise group (TCEG) randomly. SFEG and TCEG underwent exercises three times a week for 8 weeks, with three sets per day, totalling up to 5 minutes per day. The navicular drop test (NDT) was used in order to assess for changes in the medial longitudinal arch and the Cumberland ankle instability tool (CAIT) was used to assess for ankle instability of the chronic ankle sprain patients.
\end{abstract}

Results: There was a significant increase in CAIT scores in the SFEG $(p<0.05)$ and a significant difference between groups was presented $(p<0.05)$. The NDT scores were significantly decreased in both groups $(p<0.05)$. In the SFEG, the NDT scores were more decreased than in the TCEG $(p<0.05)$.

Conclusions: These results suggest that short foot exercises are more effective in providing intrinsic foot muscle training for patients with pronated feet among chronic ankle sprain patients. Furthermore, short foot exercises may be used to provide ankle stability.

Key Words: Ankle injuries, Exercise, Flatfoot, Foot

\section{Introduction}

While pursuing a socially valuable quality of life due to recent economic developments, various leisure sports activities have improved and various sports injuries have increased accordingly. Looking at studies on lower extremity injuries, ankle sprains have the highest incidences, making up to $75 \%$ of all lower extremity injuries [1]. Of ankle sprains, an inversion sprain was reported to account for more than $85 \%$ [2], and with the addition of excessive ankle pro- nation causes the calcaneous to tilt medially compared to normal, producing an unstable position, which may eventually lead to lower extremities injuries and falls. This causes a summative load in the knee joint and hip joint as well as ankle joint during gait which can lead to the display of flatfoot and pronated foot conditions [3].

Foot pronation causes pronation of the subtalar joint or mid tarsal joint during weight-bearing activities, which may increase fall risk. It might impair the stability of the foot and thus have an impact on the occurrence of plantar fasciitis,

Received: 4 May, 2016 Revised: 13 June, 2016 Accepted: 15 June, 2016

Corresponding author: Seungwon Lee

Department of Physcal Therapy, College of Health and Welfare, Sahmyook University, 815 Hwarang-ro, Nowon-gu, Seoul 01795, Republic of Korea Tel: 82-2-3399-1630 Fax: 82-2-3399-1639 E-mail: swlee@syu.ac.kr

(c) This is an Open-Access article distributed under the terms of the Creative Commons Attribution Non-Commercial License (http://creativecommons.org/licens es/by-nc/4.0) which permits unrestricted non-commercial use, distribution, and reproduction in any medium, provided the original work is properly cited.

Copyright $@ 2016$ Korean Academy of Physical Therapy Rehabilitation Science 
patellofemoral pain, or foot pain. Also, an eversion position of ankle is generated [4-6].

Pronated foot is deeply related to the medial longitudinal arch (MLA) where the presence of a pronated foot consequently leads to a decrease in the MLA [7,8], Therefore, it can be suggested that maintaining the integrity of the MLA may help prevent certain musculoskeletal conditions, and, thus, careful attention must be given to its supporting structures. The MLA is reinforced by various anatomical structures of the foot, such as actions of direct muscles as well as indirect anatomical structures such as the plantar fascia and plantar ligaments $[9,10]$, and this MLA is complemented by various methods, such as the use of insoles and exercise. The extrinsic foot musculature (EFM) was used to complement MLA in the past [11]. However, recently it has been suggested that the intrinsic foot musculature (IFM) could play a critical role in supporting the MLA as well [12]. We have mainly used toe-flexion exercises, such as towel crunches or marble pickups, in order to strengthen this IFM but toe-flexion exercises are not suitable for strengthening the IFM to complement the MLA because they also use the EFM, such as the flexor digitorum longus muscle [12].

Recently, short foot exercises (SFE) have shown to be effective using the IFM and excluding the EFM. Janda and VaVrova [13] found that SFE contracted the intrinsic muscles of the foot to increase the inner arch of the foot, thereby shortening the longitudinal arch. Although these various exercises are presented, we have not yet presented a remarkable exercise method to complement the MLA to people with pronated feet due to ankle injuries.

Consequently, in this study, we have found a more effective IFM training method that can improve the MLA of chronic ankle injured patients with foot pronation, as well as a more effective exercise method for these patients.

Table 1. Demographic characteristics of the subjects $(\mathrm{N}=30)$

\begin{tabular}{lccc}
\hline Characteristic & SFEG $(\mathrm{n}=15)$ & TCEG $(\mathrm{n}=15)$ & $\mathrm{t}(p)$ \\
\hline Age $(\mathrm{y})$ & $21.80(2.31)$ & $21.73(1.75)$ & $-0.089(0.930)$ \\
Sex (male/ & $7 / 8$ & $8 / 7$ & \\
female) & & & \\
Height $(\mathrm{cm})$ & $165.82(8.46)$ & $168.43(8.96)$ & $0.819(0.419)$ \\
Weight $(\mathrm{kg})$ & $61.62(9.45)$ & $64.21(13.68)$ & $0.602(0.552)$ \\
\hline
\end{tabular}

Values are presented as mean (SD).

SFEG: short foot exercise group, TCEG: towel curl exercise group.

\section{Methods}

\section{Subjects}

One hundred and twenty adult men and women who had experienced an ankle sprain in the past were chosen from G-University located in Gwangju. This study measured the valgus angle of the calcaneus and selected 53 people with a valgus angle of $2^{\circ}-3^{\circ}$ and with no particular medical findings. The purpose and methods of this study were explained in detail to all subjects. After being informed, subjects who agreed to participate in the study were included but were free to withdraw from the study whenever they wished, even if the study was in progress. Acute double onset patients, patients who underwent an operation and patients with mental illness were excluded. Fifty-three chronic ankle sprain patients who consented to participate in the study were selected. In order to select patients suitable for the experiment, 30 people consisting of 15 men and 15 women among patients with less than 24 points on the Cumberland ankle instability tool (CAIT) for ankle instability were selected. The physical characteristics of the subjects are summarized in Table 1.

\section{Procedure}

In this study, a pre-test was carried out to find out the changes in height of the navicular and ankle instability of the 30 selected subjects before and after the experiment and men and women were divided. Fifteen people were allocated to the short foot exercise group (SFEG) and fifteen to the towel curl exercise group (TCEG) by drawing lots through randomized controlled trial. Subsequently, the SFE and TCE were conducted for 8 weeks, respectively.

\section{Intervention}

\section{Short foot exercise}

The SFE is accomplished by shortening the foot in an antero-posterior direction and actively attempting to bring the head of the first metatarsal toward the heel without toe flexion [14]. Various methods were performed based on the previous research of Moon et al. [15]. In order to minimize error values and increase objectivity, a stopwatch (HS-70W; Casio, Tokyo, Japan) was used to measure exercise times. The exercise was carried out in a sitting position without weights for 1-4 weeks (Figure 1) and in a standing position with weights for 5-8 weeks (Figure 2). The exercises were performed 3 times per week, with three sets performed in one week totaling up to 20-25 times, and with 5 minutes 
spent per set.

\section{Towel curl exercise}

TCE is achieved by curling the toes on a towel, bunching the towel beneath the foot using interphalangeal and metatarsophalangeal flexion of the toes [16]. Various methods were performed based on previous research of Lynn et al. [17]. In order to minimize error values and increase objectivity, a stopwatch (HS-70W) was used to measure exercise time. On a slick surface (tile, hard wood floor, etc.) the exercise was carried out in a sitting position without weights for 1-4 weeks (Figure 3), and then with the addition of dumbbells of 2-4 $\mathrm{kg}$ performed at a rating of perceived exertion score of 13-15, which was considered as "slightly hard to hard" for 5 minutes in a sitting position for 5-8 weeks (Figure 4). The exercise consisted of 3 times per week, with three sets performed in one week totaling up to 20-25 times, and with 5 minutes spent per set.

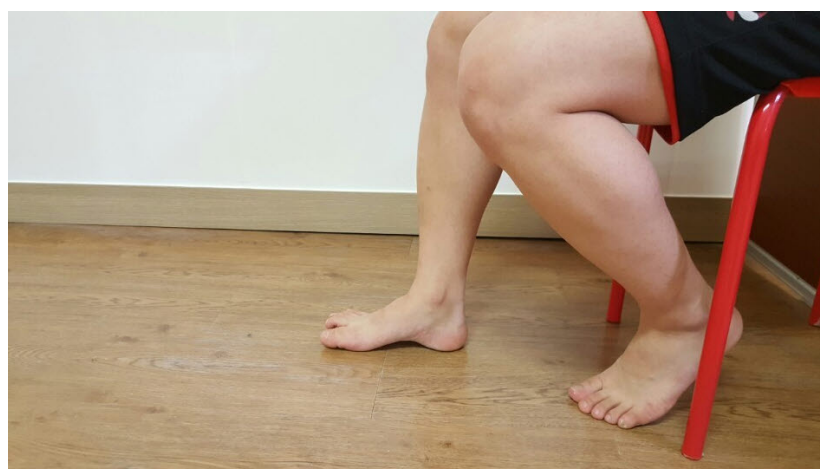

Figure 1. Short foot exercise in a sitting position without weight bearing.

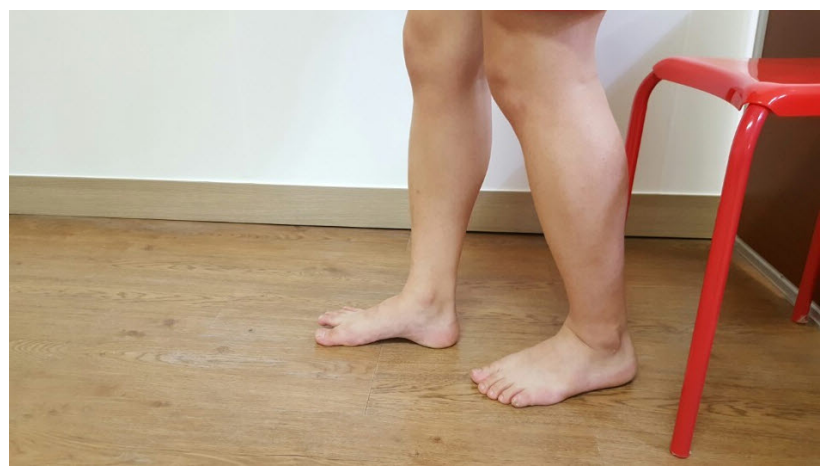

Figure 2. Short foot exercise in a standing position with weight bearing.

\section{Assessments}

\section{Ankle instability}

In order to assess for ankle instability of chronic ankle sprain patients, the CAIT (sensitivity: $82.9 \%$, specificity: $74.7 \%$ ) was used. The CAIT consists of a total of 9 questions which relate to ankle instability of the environment. Five questions consists of a score of $0-4$, two instability perception questions consists of a score of $0-4$, one pain-related question consists of a score of 0-5 and another question consist of a score of $0-2$. Based on the perfect score of 30 , more than 28 points indicates stability of the ankles while less than 24 points indicate instability. Higher scores indicate normal ankle conditions while lower scores indicate poor stability [18].

\section{Navicular drop test}

The navicular drop test (NDT) is a highly reliable test method [19] with and intraclass correlation coefficient of 0.971 [20] and serves as a highly valuable measurement method that can determine injury and weakness of the mus-

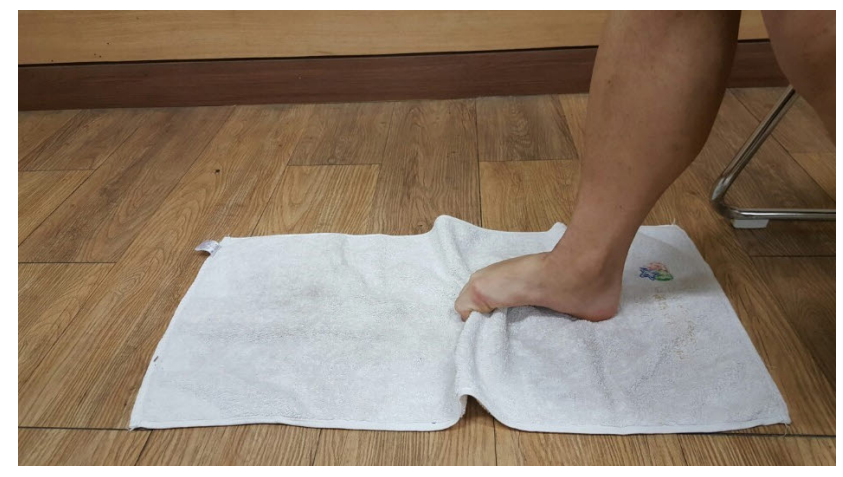

Figure 3. Towel curl exercise in sitting position without weight.

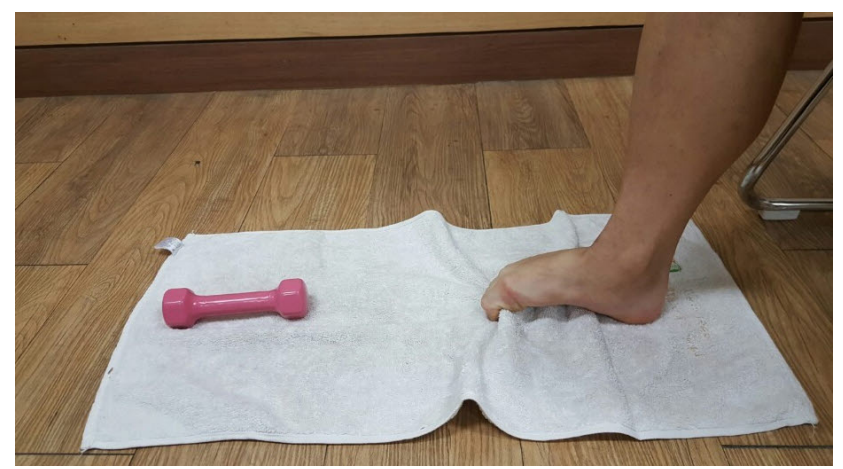

Figure 4. Towel curl exercise in sitting position adding weight. 
culoskeletal system that may cause changes in the MLA height [21].

The NDT measures the height of the navicular from the bottom in a non-weight-bearing state and in a relaxed position and then subsequently determines the degree of pronation of the feet by measuring the navicular height again while bearing weight. If there is a difference of more than $10 \mathrm{~mm}$, it is diagnosed as foot pronation [22].

The method allows the subject to comfortably sit in a chair and flex his knees at $90^{\circ}$. Then, the knee of foot and 2 nd phalangeal is to be measured in a straight line. The tester should hold the talus by hand and adjust the subtalar joint to a neutral posture and another tester should palpate and mark the tubercle of the navicular located approximately $1.5 \mathrm{inch}$ in the lower front of the lower extremity malleolus. After placing paper to be horizontal to the ground, we put paper on the marked navicular tubercle. Points were marked to measure the height from the ground to the navicular tuberosity. Then, subjects were asked to stand and maintain a gap of the calcaneus by $10 \mathrm{~cm}$ and then the height of the navicular tuberosity was measured in a comfortably weight-bearing position with both feet barefooted and placed side by side in the same method as in the sitting position.

Differences in the measured values during sitting and standing position were used. Measurements were repeated 3 times to develop a mean value and tests were conducted a total of 2 times for pre-test and post-test assessment purposes [23].

\section{Data analysis}

Mean and standard deviation of all works and statistics in this study were assessed with the use of IBM SPSS Statistics ver. 21.0 (IBM Co., Armonk, NY, USA). The Shapiro-Wilk method was used for normality test of all subjects. Descriptive statistical analysis was used for general traits of subjects. An independent t-test and paired t-test was used in

Table 2. Comparison of the CAIT for ankle instability $(\mathrm{N}=30)$

\begin{tabular}{lccc}
\hline CAIT (score) & SFEG $(\mathrm{n}=15)$ & TCEG $(\mathrm{n}=15)$ & $\mathrm{t}(p)$ \\
\hline Pre-test & $21.77(1.58)$ & $21.80(1.81)$ & $0.290(0.811)$ \\
Post-test & $25.80(1.65)$ & $22.33(1.67)$ & \\
Change value & $4.20(1.02)$ & $0.53(1.06)$ & $3.179(0.000)$ \\
$\mathrm{t}(p)$ & $16.039(<0.000)$ & $1.948(0.072)$ & \\
\hline
\end{tabular}

Values are presented as mean (SD).

CAIT: Cumberland ankle instability tool, SFEG: short foot exercise group, TCEG: towel curl exercise group. order to examine the differences between groups and compare the significance of before and after the experiment within groups respectively. The statistical significance was set as $\alpha=0.05$.

\section{Results}

\section{Differences in ankle instability}

The CAIT scores showed a significant increase from 21.77 to 25.80 , with a change value of 4.20 points, in the SFEG $(p<0.05)$ but the TCEG did not show a significant increase from 21.80 to 22.33 score, with a change value of 0.53 points $(p<0.05)$. Significant changes between groups showed a more significant increase in the SFEG $(p<0.05)$. The differences in ankle instability are summarized in Table 2.

\section{Differences in foot pronation}

The NDT was used to assess for foot pronation., For the SFEG, there was a significant decrease from $16.60 \mathrm{~mm}$ to $11.13 \mathrm{~mm}$, with a change value of $5.47 \mathrm{~mm}$ and for the TCEG, there was a significant decrease from $16.47 \mathrm{~mm}$ to $12.53 \mathrm{~mm}$, with a change value $3.93 \mathrm{~mm}(p<0.05)$. For changes between the two groups, the SFEG showed a more significant decrease in scores $(p<0.05)$. The differences in foot pronation measurements are summarized in Table 3.

\section{Discussion}

The position sense of the ankle decreases with deformation of the foot, such as flatfoot and foot pronation [3,24] In order to correct foot pronation, several studies on the MLA height have been carried out. Snyder et al. [25] presented that increasing muscle strength of the IFM and EFM is the most effective and active method to correct pronation of the joint causing the lowering of the MLA. Fiolkowski et al.

Table 3. Comparison of the NDT for navicular height $(\mathrm{N}=30)$

\begin{tabular}{lccc}
\hline \multicolumn{1}{c}{ NDT $(\mathrm{mm})$} & SFEG $(\mathrm{n}=15)$ & TCEG $(\mathrm{n}=15)$ & $\mathrm{t}(p)$ \\
\hline Pre-test & $16.60(3.52)$ & $16.47(3.20)$ & $0.108(0.914)$ \\
Post-test & $11.13(3.53)$ & $12.53(2.99)$ & \\
Change value & $5.47(2.17)$ & $3.93(1.16)$ & $2.415(0.023)$ \\
$\mathrm{t}(p)$ & $9.771(<0.000)$ & $13.100(<0.000)$ & \\
\hline
\end{tabular}

Values are presented as mean (SD).

NDT: navicular drop test, SFEG: short foot exercise group, TCEG: Towel curl exercise group. 
[26] conducted the NDT by blocking the tibial nerve delivered to the IFM and as a result, pronation in a static standing position was significantly increased, and it can be stated that IFM has a direct impact on navicular height through this study.

Previous research on IFM and navicular height was analyzed and as a result, Newsham [12] reported that SFE is more effective in excluding extrinsic foot muscles, such as the flexor digitorum longus, and for strengthening the IFM compared with TCE. Jung et al. [16] conducted an experiment on assessing muscle activity of the abductor hallucis using electromyography and had the maximum voluntary isometric contraction of the abductor hallucis muscle measured in the manual muscle-testing position. As a result, both sitting and standing on one leg positions showed more significant effects in SFE (sitting: 45.2, one leg standing: 73.2) than in TCE (sitting:10.1, one leg standing: 17.5) $(p<0.001)$.

Also, when comparing SFE $\left(139.8^{\circ}\right)$ and TCE $\left(146.2^{\circ}\right)$ for the MLA angle in the study of Jung et al. [16], standing on one leg position showed a significant decrease $(p<0.001)$.

In this study, the navicular height showed a significant decrease in both groups, by $5.47 \mathrm{~mm}$ in the SFEG and $3.93 \mathrm{~mm}$ in the TCEG $(p<0.05)$ The SFEG of both groups showed a more significant decrease $(p<0.05)$ After comparing and analyzing the result values of the previous research, it can be seen that the SFE is more effective in IFM training than TCE. As presented by Newsham [12], the reason is thought to be due to the fact that SFE excludes extrinsic foot muscles more than TCE and not only focuses on IFM training but uses the tibialis posterior muscle directly affecting MLA. Given a number of studies that IFM is effective in increasing the height of the MLA, it can be seen that SFE is more effective in increasing the navicular height and correcting foot pronation.

Repeated ankle sprains have developed into a chronic instability, causing instability of the ankle [27]. Witchalls et al. [24] pointed out that decreased proprioceptive sense or joint position sense as the biggest causes of ankle instability. McKeon et al. [28] introduced the concept of the foot core and called for an increased awareness of the importance of foot core stability for normal feet and lower extremity functions. This study measured the ankle instability to compare the sensory aspect. SFEG showed a significant increase from 21.77 to $25.80(p<0.05)$ but TCEG showed an increase from 21.80 to $22.33(p<0.05)$.

Janda and VaVrova [13] stated that SFE maintains the position of body segments and improves trunk stability by stimulating the somatosensory afferent pathway from the sole. It was described as the first step in proprioception training. Also, Lee's study [29] presented that SFE is significantly more effective for ankle instability than balance exercise $(p<0.05)$.

When summarizing the findings of the previous studies and for this study, it can be seen that both SFE and TCE have been used in IFM training but SFE is a training method which is more effective in accepting afferent information during contraction.

According to the experimental results, both SFE and TCE were effective in NDT. SFE produced more effective results and also, improved results for ankle instability were shown only with SFE.

Based on these findings, the structure of the MLA undergo through more effective training for patients with foot pronation accompanied by ankle sprains with IFM. Also, exercise methods which are more effective in treating ankle instability will be presented.

\section{Conflict of Interest}

The authors declared no potential conflicts of interest with respect to the authorship and/or publication of this article.

\section{References}

1. Lambers K, Ootes D, Ring D. Incidence of patients with lower extremity injuries presenting to US emergency departments by anatomic region, disease category, and age. Clin Orthop Relat Res 2012;470:284-90.

2. Cox JS. Surgical and nonsurgical treatment of acute ankle sprains. Clin Orthop Relat Res 1985;(198):118-26.

3. Flemister AS, Neville CG, Houck J. The relationship between ankle, hindfoot, and forefoot position and posterior tibial muscle excursion. Foot Ankle Int 2007;28:448-55.

4. Kennedy JG, Knowles B, Dolan M, Bohne W. Foot and ankle injuries in the adolescent runner. Curr Opin Pediatr 2005; 17:34-42.

5. Yamashita MH. Evaluation and selection of shoe wear and orthoses for the runner. Phys Med Rehabil Clin N Am 2005; 16:801-29.

6. Taunton JE, Ryan MB, Clement DB, McKenzie DC, Lloyd-Smith DR, Zumbo BD. A retrospective case-control analysis of 2002 running injuries. Br J Sports Med 2002;36:95-101.

7. Busseuil C, Freychat P, Guedj EB, Lacour JR. Rearfoot-forefoot orientation and traumatic risk for runners. Foot Ankle Int 1998;19:32-7.

8. Hintermann B, Nigg BM. Pronation in runners. Implications for injuries. Sports Med 1998;26:169-76.

9. Borton DC, Saxby TS. Tear of the plantar calcaneonavicular 
(spring) ligament causing flatfoot. A case report. J Bone Joint Surg Br 1997;79:641-3.

10. Fuller EA. The windlass mechanism of the foot. A mechanical model to explain pathology. J Am Podiatr Med Assoc 2000;90:35-46.

11. Thordarson DB, Schmotzer H, Chon J, Peters J. Dynamic support of the human longitudinal arch. A biomechanical evaluation. Clin Orthop Relat Res 1995;(316):165-72.

12. Newsham KR. Strengthening the intrinsic foot muscles. Athl Ther Today 2010;15:32-5.

13. Janda V, VaVrova M. Sensory motor stimulation. Baltimore: Williams \& Wilkins; 1996. p. 319-28.

14. Prentice WE. Rehabilitation techniques in sports medicine. 4th ed. New York: McGraw Hill Higher Education; 2009. p. 40-59.

15. Moon DC, Kim K, Lee SK. Immediate Effect of Short-foot Exercise on Dynamic Balance of Subjects with Excessively Pronated Feet. J Phys Ther Sci 2014;26:117-9.

16. Jung DY, Kim MH, Koh EK, Kwon OY, Cynn HS, Lee WH. A comparison in the muscle activity of the abductor hallucis and the medial longitudinal arch angle during toe curl and short foot exercises. Phys Ther Sport 2011;12:30-5.

17. Lynn SK, Padilla RA, Tsang KK. Differences in static- and dynamic-balance task performance after 4 weeks of intrinsic-foot-muscle training: the short-foot exercise versus the towel-curl exercise. J Sport Rehabil 2012;21:327-33.

18. Sawkins K, Refshauge K, Kilbreath S, Raymond J. The placebo effect of ankle taping in ankle instability. Med Sci Sports Exerc 2007;39:781-7.

19. Moore KL, Dalley AF, Agur AM. Clinically oriented anatomy. 2nd ed. Baltimore: Williams \& Wilkins; 1985.

20. Vinciguerra G, Belcaro G, Cesarone MR, Errichi BM, Di Renzo A, Errichi S, et al. Management of uncomplicated ankle sprains with topical or oral ketoprofen treatment. A registry study. Minerva Cardioangiol 2008;56(5 Suppl):47-53.

21. Allen MK, Glasoe WM. Metrecom measurement of navicular drop in subjects with anterior cruciate ligament injury. J Athl Train 2000;35:403-6.

22. Magee DJ. Orthopedic physical assessment. 5th ed. St. Louis: Saunders Elsevier; 2008.

23. Kim TH, Koh EK, Jung DY. The effect of arch support taping on plantar pressure and navicular drop height in subjects with excessive pronated foot during 6 weeks. Korean Soc Phys Med 2011;6:489-96.

24. Witchalls J, Waddington G, Blanch P, Adams R. Ankle instability effects on joint position sense when stepping across the active movement extent discrimination apparatus. J Athl Train 2012;47:627-34.

25. Snyder KR, Earl JE, O'Connor KM, Ebersole KT. Resistance training is accompanied by increases in hip strength and changes in lower extremity biomechanics during running. Clin Biomech (Bristol, Avon) 2009;24:26-34.

26. Fiolkowski P, Brunt D, Bishop M, Woo R, Horodyski M. Intrinsic pedal musculature support of the medial longitudinal arch: an electromyography study. J Foot Ankle Surg 2003;42: 327-33.

27. Beynnon BD, Renström PA, Alosa DM, Baumhauer JF, Vacek PM. Ankle ligament injury risk factors: a prospective study of college athletes. J Orthop Res 2001;19:213-20.

28. McKeon PO, Hertel J, Bramble D, Davis I. The foot core system: a new paradigm for understanding intrinsic foot muscle function. Br J Sports Med 2015;49:290.

29. Lee ES. Effects of intrinsic foot muscle training on proprioception [Master thesis]. Seoul: Sahmyook University; 2015. 